\title{
De la verticalidad a la borizontalidad. Reflexiones para una educación emancipadora
}

\author{
Marcos Santos Gomez \\ Universidad de Granada
}

RESUMEN: El autor del presente ensayo busca concretar algunos aspectos relacionados con la educación entendida como labor emancipadora. Si ésta persigue la autonomía del educando, contra algunas realidades opresivas, babría de apuntar a un cierto tipo de hombre y de sociedad. Para perfilar esta idea, se comparan dos formas de estar en el mundo y de relación entre las personas. La primera se denomina "verticalidad", e implica la estratificación social junto con una dinámica psiquica que tiende a jerarquizar a las personas seguin escalas interionizadas por el individuo a través de la educación reproductora. Se destaca su fuerte carácter alienante y opresor. $A$ ella se ba confrontado una segunda perspectiva, denominada "horizontalidad", porque supone un modelo de sociedad fratemal $e$ igualitaria, pero que sobre todo implica un nuevo modo "respetuoso" de entender la relación con el otro. Sería la consecución de esta apertura bacia el prójimo, asumida por el individuo y las estructuras sociales, el objetivo de toda educación que pretenda ser emancipadora, ya que sólo desde dicha disposición receptiva se favoreceria el surgimiento de individuos autónomos.

ABSTRACT: The following essay pursues to concrete some aspects which are related with the education conceived as an emancipating

De la vertledidad a la hariratdided. Reflexlones pora una educaclón emenclpadora. 
labor. If this kind of education pursues the pupil's autonomy against some oppressive realities, one must point to certain kind of person and society. In order to shape this idea, two forms of being in the world and of buman relationships are compared. The first one is called "verticality" and implies the social stratification with a psychic dynamics which tends to create hierarchies among persons, according with interiorized scales through the reproductive education. Its alienating and oppressing power is outlined. This conception is confronted with other perspective, called "borizontality", for this suppose a new and respectful way to understand the relations with others. The prosecution of this openness to the others, assumed by the individual and the social structures, would be the aim of every education that pretends to be emancipating, because only from this perspective the creation of autonomous individuals would be favored.

\section{Introducción y objetivos}

Lo que vamos a proponer en las líneas que siguen es la creación del medio adecuado para la libre expresión del educando. Subyacerá a nuestra exposición una idea de educación como proceso socrático que busca la expresión auténtica y sincera del educando, a través de la interacción sin trabas con los otros. En este sentido, educar sería realizar y promover dicho proceso, procurando un entorno social adecuado que lo facilite. En esta línea, más o menos, concibe Rousseau su pedagogía (Rousseau, 1998) y, de uno u otro modo, también lo hace un buen número de las pedagogías "radicales" posteriores, hasta nuestros días. (Ayuste, 1999, 23-25; Spring, 1987)

Como es sabido, el proyecto rousseauniano de educación procura la búsqueda de un entomo que no obstaculice el desarrollo de la naturaleza bondadosa del hombre, lejos de la corrupción de una sociedad construida en oposición a dicha naturaleza. En el presente artículo latirá esta idea base que nosotros enfocaremos desde la perspectiva de algunas pedagogías actuales y filosofías que han buscado esa liberación humana y entroncan con el pensamiento del filósofo ginebrino. Y en esta búsqueda destacaremos que, para que la educación sirva verdaderamente a la referida concepción emancipadora, debe apuntar a lo interno y a lo externo en el educando, considerando aportaciones de la psicología y la reflexión social. Hablaremos de ellas, resaltando que la liberación implica una transformación tanto interior como exterior del hombre. 
Retomaremos en parte el alegre optimismo ilustrado, pero a sabiendas de que a estas alturas resulta difícil asumirlo en su ingenua pureza. Nos decantaremos, pues, por cierto optimismo que contrastará, desde luego, con el pesimismo manifestado por numerosos autores contemporáneos, como el último Horkheimer (Estrada, 1990) y que los tenebrosos hechos de la historia reciente cuyo paradigma es Auschwitz nos ponen en duda. (Adorno, 1998, 79-92) En resumidas cuentas, vamos a llevar a cabo una crítica de ciertas realidades humanas opresivas creadas por el propio hombre, paradójicamente contra sí mismo, a la par que sugeriremos una propuesta utópica para la superación de tales realidades a favor del hombre. Intentaremos presentar una interpretación, por un lado, de la posible naturaleza de esa opresión que se opone a la felicidad del hombre y, por otro, sugerir las posibilidades de una liberación factible en la que como principal agente se hallaría implicada la educación.

Es justamente esto lo que plantea el psicólogo Erich Fromm, al cual acudiremos a menudo. Su perspectiva, que aúna psicología con reflexión y crítica social, nos parece bastante sugerente y muy representativa de interesantes corrientes del pensamiento del siglo XX. (Taberner, 1988) Para él, racionalizar la vida no es intelectualizarla, como se ha creído, sino humanizarla, es decir, hacer que responda a las necesidades específicamente humanas. (Fromm, 1992; 1999) Esta humanización implica el desarrollo de una equilibrada vinculación afectiva con los otros hombres y con el mundo, ya no basada en la posesión, sino en una suerte de amor maduro que describe bellamente y reviste de un cierto estilo fraternal que podríamos asociar al igualitarismo político. (Fromm, 1974) Partiremos de sus reflexiones y profundizaremos en ellas, demostrando, en la medida en que podamos, la humana necesidad de fraternidad, acercándonos lo más posible al ámbito de estudio de la "Filosofía de la educación". Porque, lo que él nos presenta no es una problemática ajena a la pedagogía contemporánea y a él podemos asociar las concepciones de autores ya clásicos de la misma, como A. S. Neill, cuya obra principal prologa. (Neill, 1994)

Así pues, se puede afirmar con Fromm que no vivimos vidas plenamente humanas y productivas. En esto coinciden otros autores afines, que han coincidido en que nos desviamos de un modelo de sociedad donde el hombre podría realizarse y acercarse a su felicidad. (vg. Marcuse, 1998; Reich, 1985)' Nosotros, a continuación, vamos a destacar algunos de los aspectos que empobrecen nuestra existencia y nos oprimen. Resaltaremos cómo, ciertamente, obstaculizan la consecución de la felicidad 
para todos los hombres, hoy por hoy, independientemente de su posición social. Y esto último resultará lo más difícil de demostrar. Porque, aunque la opresión es mucho más evidente en quien se sitúa en la base de la pirámide social, también se halla en el corazón del que se ubica, o es ubicado, arriba. Intentaremos mostrar cómo lo que denominaremos a partir de ahora "verticalidad", desde cualquier punto en que nos coloquemos, corrompe profundamente al hombre y oprime su corazón. Todo esto lo confrontaremos, en la segunda parte del presente escrito, con el esbozo de una utopía relacionada con una hipotética "borizontalidad" que sí permitiría la plena realización del hombre.

\section{La verticalidad: la opresión del mundo como teatro}

Por verticalidad entendemos, en una primera aproximación, una forma de concebir el mundo que tiene su reflejo en el modelo piramidal de la sociedad. Nos referimos a una determinada lógica en la percepción del mundo y en las relaciones humanas, que funciona jerarquizando a los hombres y produciendo estructuras verticales en las sociedades. Esto quiere decir que hay una forma vertical de entender el mundo.

Lo que denominamos verticalidad es una idea central en ciertos autores que tendremos muy presente, los cuales han estudiado el autoritarismo de un modo u otro. (Horkheimer, 1998, 95-222; Reich, 1972 y 1985; Fromm, 1976) Pero, como ya hemos avanzado, nos centraremos en el arriba mencionado psicólogo y pensador Erich Fromm. Es este autor quien desarrolla magníficamente la idea que deseamos presentar, definiendo además la noción de "carácter social" que nosotros presuponemos a lo largo de nuestro trabajo. (Fromm, 1992, 71-90) El "carácter social" es, según nos explica, el tipo de forma de ser requerido por una estructuración social determinada. Es decir, una determinada sociedad, a través de los procesos de socialización, procura la configuración mental que sirve a su reproducción ${ }^{2}$. En relación con esto, resulta inevitable acudir además al sociólogo Bourdieu, quien introduce la noción de "habitus" como el conjunto de pautas, estilos y contenidos culturales que caracterizan a un sector de la pirámide social y que contribuye a la aceptación del lugar ocupado en la escala social como algo natural. (Bourdieu, 2000) Se trata de una especie de sub-cultura de clase que garantiza, entre otras cosas, la endogamia social. En sus estudios de carácter empírico se patentiza el extremo grado en que somos hechos según los intereses y la lógica de la estructuración piramidal (vertical) de la sociedad. En efecto, hemos 
interiorizado una serie de esquemas que rigen nuestras pautas de conducta y que pasan a constituirnos como si hubiéramos nacido con ellos. (Peña y Rodríguez, 2002, 238-239) Por eso, esta potente socialización reproductora genera un fatalismo en la concepción de la realidad, considerada inmodificable y eterna en la forma que presenta en el tiempo actual. Esto, por supuesto, obstaculiza todo cambio sustancial en el sistema social. (Bourdieu y Passeron, 2001)

El fuerte arraigo de la mentalidad fatalista en el individuo, incluso en quien más razones tendría para cambiar las cosas, es denunciado por el conocido pedagogo Paulo Freire. Se trata de una denuncia presente a lo largo de toda su producción, hasta los últimos libros, escritos al final de su vida en el contexto de la actual oleada de neoliberalismo y conservadurismo. (Freire, 2001; 2002) Este fatalismo adquiere tintes dramáticos en ciertos ejemplos reales que presenta, en cuanto estado profundamente destructor que se instala en el alma del oprimido. Así, nos describe la situación de un joven trabajador temporero del campo en Brasil:

La amargura de la existencia de aquel adolescente era tan profunda que su presencia en el mundo se transformaba en una pesadilla, una experiencia en la cual era imposible soñar. 'Sólo tengo pesadillas', repitió, como si insistiese para que el reportero jamás olvidase esta situación. Él no veía un futuro para sí. (Freire, 2002, 37)

El concepto de "ideología" apunta precisamente a esta función legitimadora que ostentan las creencias (Marx, 1993). Como es bien conocido, hay numerosísimos estudios al respecto. El papel determinante que las ideologías cumplen en la reproducción y consolidación de las estructuras de clase es explicado por autores de cierto corte marxista como Gramsci, Lukacs, Horkheimer o Marcuse'. Hemos de señalar que, cuando enarbolamos este concepto en el presente trabajo, nos referimos a creencias firmemente inscritas en el individuo, en lo más hondo de su carácter, tan ligadas al propio ser como las células o la sangre. Es Fromm quien mejor lo pone de manifiesto, con la claridad que lo caracteriza. Así, en cierta obra vincula la conducta y las relaciones posesivas de los hombres con un tipo específico de personalidad competitiva, de modo de estar en el mundo. Frente a esta visión de la realidad, contrasta la del hombre cuya vida y psique se entienden desde la noción de "ser". (Fromm, 1999) 
La verticalidad como manera de pensar y percibir la realidad es, desde luego, una ideologia, en tanto que pensamiento legitimador de una sociedad caracterizada por la escisión y separación entre sus miembros. Implica la ordenación, a menudo inconsciente, que el sujeto hace de las demás personas, una ordenación vertical en la que se sirúa a él y a los demás en una escala de arribas y abajos. Por eso, el sujeto se torna competitivo, rivalizando con el otro y cosificándolo, en la medida en que lo considera sólo según su situación respecto a los grados o escalones de la jerarquía interionizada. Según esto, la persona del otro tiende a tratarse como un objeto. El sujeto inscrito en la verticalidad filtra y elimina todo lo humano presente en el prójimo y se queda con el tipo o etiqueta que lo clasifica La verticalidad implica, por tanto, un tipo de mirada superficial por la que los sujetos se acorazan en los clichés que los sitúan y legitiman en el status deseado. En este sentido, la vida humana y las relaciones sociales se convierten en una búsqueda de avales que justifiquen la posición del sujeto en un escalón elevado, dentro de la escala asumida. Se desea dicha aprobación desde lo más profundo del individuo. Por eso, las relaciones humanas se convierten en un patológico juego de sumisión y dominio, en un proceso cuyo fundamento es el ejercicio del dominio y del poder. (Fromm, 1976) Así lo demuestran también los inquietantes estudios de Foucault, que también subraya esta omnipresencia de un poder que lo impregna todo en las relaciones humanas, en sus niveles aparentemente más alejados de la pirámide política. "Poder que no está tan sólo en las instancias superiores de la censura, sino que penetra de un modo profundo, muy sutilmente, en toda la red de la sociedad." (Foucault, 2001, 25) ${ }^{4}$ Vemos, pues, que topamos con una realidad profundamente arraigada en el hombre actual.

El problema de la situación que estamos describiendo es que, según constatan los autores freudomarxistas, en toda verticalización hay una suerte de enajenación, con la consecuente pérdida de libertad y autenticidad en el sujeto humano.

El elemento común a la sumisión y el dominio es la naturaleza simbiótica de la relación. Las dos personas afectadas han perdido su integridad y su libertad; viven la una de la otra y la una para la otra, satisfaciendo su anhelo de intimidad, pero sufriendo por la falta de fuerza y de confianza interiores, que requieren libertad e independencia, y además están constantemente amenazadas por la hostilidad consciente o inconsciente que nace de la relación simbiótica. (Fromm, 1992, 33) 
Es decir, la persona vertical ha colocado su voluntad en manos de los otros, erigidos en jueces de la propia valías.

Así pues, esta persona que asume las escalas sociales en lo más profundo de su carácter y se identifica con ellas está alienada. Recogemos la definición de alienación (o enajenación) del propio Fromm, ya clásica:

Entendemos por enajenación un modo de experiencia en que la persona se siente a sí misma como un extraño. Podría decirse que ha sido enajenado de sí mismo. No se siente a sí mismo como centro de su mundo, como creador de sus propios actos, sino que sus actos y las consecuencias de ellos se han convertido en amos suyos, a los cuales obedece y a los cuales quizás hasta adora. La persona enajenada no tiene contacto consigo misma, lo mismo que no lo tiene con ninguna otra persona. Él, como todos los demás, se siente como se sienten las cosas, con los sentidos y con el sentido común, pero al mismo tiempo sin relacionarse productivamente consigo mismo y con el mundo exterior. (Fromm, 1992, 105)

Terribles consecuencias para el individuo. La persona se anula y llega a convertirse en un personaje, desenvolviéndose en la tramoya social como un actor que interpreta un papel escrito por otros. El sujeto espera el reconocimiento público de su "trabajo", de su esfuerzo histriónico. Pretende merecer la mirada aprobadora del "juez social" y se convierte él también, por supuesto, en un implacable juez que sitúa a los demás en la escala social interiorizada.

En definitiva, la mirada del bombre o la mujer vertical se empobrece en tanto que pierde su profundidad y se detiene en el cliché que ella misma coloca en la realidad. Las relaciones entre los sujetos se basan en pautas y comportamientos esperados, socialmente requeridos, de manera que se ritualizan. Cesa la espontaneidad y la imprevisibilidad del trato humano es sustituida por la norma. El ejemplo más evidente, y quizás más trivial, es el riguroso protocolo de la aristocracia: todo un ritual que hay que aprender y que designa a quienes están dentro o fuera de ese universo de privilegios. Y el sujeto pasa la vida en un intento desesperado de obtener los símbolos de su grado, en la búsqueda envidiosa de la distinción que lo sitúe por encima de los demás. (Bourdieu, 2000)

Además, y como se desprende de lo ya expuesto, la verticalidad imposibilita el diálogo real y la búsqueda, necesariamente colectiva ${ }^{6}$, de la verdad. $E l$ 
dialogo auténtico no existe en la pirámide. Porque una persona convencida en su fuero interno, a menudo de manera inconsciente, de que los seres humanos somos cosas, objetos mensurables o no más que seres cuantificables, resulta imposible que adopte una apertura sincera al otro. No cree que la otra persona valga, que de ella pueda proceder sabiduría. Del otro sólo le interesa la etiqueta con la que lo cataloga y que lo sitúa abajo o arriba de nosotros. No se halla psicológicamente dispuesta a recibir lo que pueda ofrecerle el otro. En la medida en que, como hemos dicho, la mente vertical jerarquiza y segrega, ¿cómo puede incluir sinceramente la opción del otro en el diálogo como búsqueda de la verdad o, simplemente, en el acuerdo práctico? En las alturas de la pirámide existe una sangrante sordera, muchas veces, al clamor del otro, porque la apertura a la borizontalidad que incluye a todas las voces resulta imposible si se teme escucharlas. No se puede aceptar a un otro del que nos protegemos, temerosos, porque cuestiona nuestro lugar inmutable en un catálogo de seres, clasificados según su valía.

De manera clara, podemos constatar que de esta actitud interna, de carácter psíquico, que hemos descrito, se alzan unas consecuencias sociales específicas. La verticalidad como carácter social se relaciona y combina con una serie de características especiales de la sociedad que aparecen intimamente ligadas a ella. Porque, como ya hemos sugerido en líneas anteriores, la verticalidad cumple un fuerte papel ideológico, en el sentido de que legitima y sirve al fortalecimiento de un modelo concreto de sociedad, de una forma de estructuración estratificada de la misma. Así, resulta ostensible la relación entre la alienación vertical cuya descripción nos ha ocupado hasta ahora, con la enajenación de una sociedad escindida, consumista y meritocrática. Volvemos a remitirnos a los inquietantes estudios de Bourdieu, que explicitan esta relación entre la configuración personal de los individuos, sus gustos y creencias, con el lugar que ocupan en la sociedad. (Bourdieu, 2000) No obstante, abundan los estudios ya clásicos en este sentido de algunos autores fundamentales en el pensamiento del siglo XX, que hemos mencionado en líneas anteriores.

Sociedad vertical y cosificadora es, desde luego, nuestra sociedad administrada y burocrática, en la que el sujeto se halla perdido y alienado, con una amarga sensación de falta de libertad y asfixia, víctima de su papel en la representación social, sometido a una lógica ajena. Quien posiblemente mejor denuncia esta situación de carga psíquica, en la literatura contemporánea, es el atormentado escritor Franz Kafka'. El mundo que nos describe a lo largo de su terrorífica obra no es precisamente 
un lugar de expresión y desarrollo del potencial humano y la creatividad, sino que supone, al contrario, una profunda merma del espíritu. En este sentido podemos hablar perfectamente, como hace Freire, de opresión. Y resulta patente que el oprimido ya no es sólo el pobre o el que peor lo pasa por estar en la base del entramado piramidal, sino que también lo es el que se instala en los niveles superiores, donde no deja de sufrir la carga de una estructura inhumana La inhumanidad de verse obligado a responder a unas expectativas y representar un papel que lo distancia del otro, la violencia de relacionarse con el otro desde la lógica del dominio y la existencia ritualizada. Desde luego, también vive el opresor un inhumano aislamiento que esclerotiza su vida ${ }^{8}$.

A continuación, tras haber presentado y descrito lo que hemos denominado verticalidad, junto con los inconvenientes que acarrea para la existencia humana, vamos a intentar argumentar sobre una posible alternativa. Esto es un propósito mucho más difícil de llevar a cabo y no podremos evitar ser algo menos precisos en las descripciones de algo que no deja de ser, hoy por hoy, una utopía. Básicamente, vamos a procurar una fundamentación de una forma diferente de estar en el mundo y con los demás hombres, que en oposición a la desarrollada en líneas anteriores, vamos a denominar horizontalidad. Pretendemos discutir, desde ahora, sobre la posibilidad y condiciones de una borizontalización de la sociedad $y$, sobre todo, del corazón del hombre.

\section{La horizontalidad como ámbito del encuentro y la escucha}

Como ya hemos adelantado, en esta última parte vamos a desarrollar una determinada concepción de la educación, que vincularemos a la idea de bonizontalidad. Hemos, por tanto, de describir primero qué entendemos por horizontalidad, qué uso vamos a hacer de este concepto. De manera general, con él aludimos a una vieja idea ilustrada, la expresada también con la palabra "fraternidad", o utopía de una "sociedad de hermanos". Y podemos retroceder aun más, pues la idea es tan vieja como el cristianismo, el estoicismo, algunas utopías del Renacimiento e incluso ciertos mitos que desarrollan la idea de una edad de oro donde no existía el odio de los hombres entre sî́.

Pero, matizando algo más, nosotros entendemos la borizontalidad como una disposición psíquica y social, interior y exterior al sujeto, en la cual ningún hombre anula la libre expresión de otro, de manera que todos pueden manifestarse sin hallar un obstáculo en el otro, sino más bien un 
apoyo para el propio crecimiento. Desde luego, para que esto ocurra ha de darse una cierta igualdad de derecho entre los individuos, siendo preciso que la sociedad adopte un tipo de estructura política de corte democrático. Pero la horizontalidad impregna ámbitos mucho más profundos en el hombre: los de su carácter. De nuevo, como en la verticalidad, tenemos una estrecha conexión que une lo interno y lo externo del hombre. En la borizontalidad, el tipo de relación entre los individuos está basado en la ayuda mutua, lejos de toda relación de dependencia y dominio, propias, como vimos, de la configuración vertical. La clave, y en esto continuamos fundamentalmente siguiendo a Erich Fromm, es la aparición en la psique del individuo de un auténtico interés por el otro ${ }^{10}$.

Se puede concebir el aspecto interno o caracterológico de la horizontalidad como una suerte de receptividad y apertura al otro. Nos referimos a una propensión íntima a la escucha y el diálogo, a la inclusión del projimo y la tolerancia". Es la actitud mental que resulta imprescindible para el diálogo auténtico. Porque resulta casi imposible que el diálogo ocurra sin una apertura al otro, que parte de la íntima convicción, en los niveles más profundos de la psique, de que el otro vale, de que puede aportarnos algo'2.

\subsection{La toma de consciencia del valor del Otro}

La necesidad de la horizontalidad queda explicada a partir del hecho señalado por Jaspers de que "si yo sólo soy yo, sería árido desierto". (Jaspers, 1958, I 458) Es decir, "yo no puedo llegar a ser yo mismo, si el otro no lo es, yo no puedo estar cierto de mí si no estoy también cierto del otro," (Jaspers, 1958, I 458) En las páginas donde se encuentran estas citas desarrolla el filósofo Jaspers, con su habitual estilo sobrio, la idea de que "yo no soy yo si no es a través de la comunicación (existencial) con un tú libre". Si aceptamos esto, nos vemos abocados a la construcción de una estructura social que propicie el encuentro con el otro. El extremo valor que éste tiene para nosotros requiere que nos ubiquemos frente a él en términos de igualdad, de manera que podamos comunicarnos, más allá de los prejuicios verticales que operan cosificándolo.

Es decir, se necesita una situación de igualdad y confianza que no coarte la libre expresión de cada existencia, en la que nadie tema ser él mismo u obligue al otro a mostrarse de manera falsa. Se precisa un tipo de relación horizontal para que los hombres, al comunicarse, se expresen y crezcan. Bien es cierto que Jaspers restringe esto a la comunicación 
entre amigos, en lo que él denomina "comunicación existencial". En ésta, el sujeto es consciente de la importancia de la comunicación para el autodesarrollo: "la conciencia de ser un factor decisivo para sí mismo y para el otro empuja a estar en la disposición más extrema para la comunicación." (Jaspers, 1958, I 458) Tanto que "toda pérdida y fallo en la comunicación es propiamente una pérdida del ser." (Jaspers, ib. 459) En esta suerte de relación horizontal y respetuosa que nos describe el filósofo alemán nos va el propio ser.

Según sus propias palabras, "en la comunicación, por virtud de la cual yo me sé captado a mi vez, el otro es solamente este otro: su singularidad es el modo en que se manifiesta la sustancialidad de este ser." (Jaspers, $i b$. 459) La otra persona es sujeto irrepetible y singular, lo cual es una verdad que, como psiquiatra, él mismo conoció bien y consideró en la práctica médica. (Jaspers, 2001) Es en esta comunicación directa y profunda en la que el sí mismo, por emplear la expresión jasperiana, se conoce y se recrea. En ella se da una creación mutua en la que los sujetos participantes se van implicando. En este juego, y sólo en él, el sujeto llega a nacer y conocerse, y trascenderse. Por eso, tiene sentido ostentar la tesis de que mi autodesarrollo requiere de la libertad y el libre desarrollo del otro. En cualquier caso, Jaspers no ignora los límites y dificultades de la comunicación existencial (Jaspers, 1958, I 459-461), pero insiste en la importancia vital para el propio individuo de que se encuentren modos de llevarla a cabo.

De un modo u otro es el acecho e irrupción de la verticalidad el principal obstáculo a esta suerte de relación fraternal entre los hombres que ahora nos ocupa. Porque la verticalidad puede interponerse entre dos personas y está en el origen de numerosos conflictos y de la ausencia de entendimiento entre los hombres. Esto se ejemplifica con claridad en el tipo de amor patológico que Fromm denomina "amor idolátrico":

Una forma de pseudoamor, que no es rara y suele experimentarse ( $y$ más frecuentemente describirse en las películas y las novelas) como el 'gran amor', es el amor idolátrico. Si una persona no ha alcanzado el nivel correspondiente a una sensación de identidad, de yoidad, arraigada en el desenvolvimiento productivo de sus propios poderes, tiende a 'idolizar' a la persona amada. Está enajenada de sus propios poderes y los proyecta en la persona amada, a quien adora como al summum bonum, portadora de todo amor, toda luz y toda dicha. En ese proceso, se priva de toda 
sensación de fuerza, se pierde a sí misma en la persona amada, en lugar de encontrarse. (Fromm, 1974, 106)

Vemos cómo en este tipo de relación humana, tan inocente en apariencia, se nos cuela esta visión y concepción del mundo que hemos denominado "vertical". El sometimiento afectivo a la otra persona que describe Fromm se entiende dentro de una concepción vertical de las relaciones humanas, de una configuración psíquica vertical. En este sentido, también el propio Jaspers afirma, sin dejar ninguna duda al respecto, que "El instintivo anhelo de que los otros debieran ser como dioses y santos impide toda comunicación." (Ib. 460)

Así pues, la interacción humana, al menos la que Jaspers denomina "existencial", nunca es un mero desarrollo de un yo innato, sino una creación del yo en la comunicación mutua. Del otro parte la construcción de uno mismo. Se trata de un bonito matiz que nos enfatiza la imperiosa necesidad de comunicarnos para crecer, de contar abiertamente con los demás, de un trato enriquecedor con el otro, que verdaderamente nos modifica irrumpiendo gozosamente en nuestra vida. Como asevera el profesor Bernal, al referirse en cierto artículo reciente a la construcción de la identidad personal, ésta se produce en la interacción con el otro (Bernal, 2003, 131). Lo que nos dota de identidad es la alteridad, lo que procede de fuera nos produce.

Será el filósofo Lévinas quien acentúe, especialmente, este carácter básico y vital para el individuo, en su soledad, de la relación ética con el otro. Cuando este autor se refiere a la ética, entiende por ésta la relación básica y fundacional con lo ajeno. Por eso, para este autor, la ética precede a toda sabiduría y entronca con profundidades muy por debajo de los discursos y las elaboraciones racionales. (Lévinas, 1999) "Un cuestionamiento del Mismo - que no puede hacerse en la espontaneidad egoísta del Mismo- se efectúa por el Otro. A este cuestionamiento de mi espontaneidad por la presencia del Otro, se llama ética." (Lévinas, $1999,67)$ Y sin esta relación ética, o irrupción del Otro que nos cuestiona, si sólo partimos de la autarquía del solitario Mismo, el pensamiento deviene injusticia: "Filosofía del poder, la ontología, como filosofía primera que no cuestiona el Mismo, es una filosofía de la injusticia." (Lévinas, 1999, 70) Podemos descubrir que, en el fondo, el otro siempre ha estado en nosotros, incluso en nuestra libertad, propiciándola, como punto de partida ${ }^{13}$. 
El otro, según la concepción levinasiana, es un rayo que nos atraviesa, un contacto que nos produce una apertura al infinito. Pero sobre todo, antes que una idea o un discurso, este Otro Maestro es un rostro. Se trata de un contacto de carne y hueso, pre-racional: "El modo por el cual se presenta el Otro, que supera la idea de lo Otro en mí, lo llamamos, en efecto, rostro." (Lévinas, 1999, 74)

La experiencia absoluta no es develamiento sino revelación: coincidencia de lo expresado y de aquel que expresa, manifestación, por eso mismo privilegiada del Otro. El rostro es una presencia viva, es expresión. La vida de la expresión consiste en deshacer la forma en la que el ente, que se expone como tema, se disimula por ella misma. El rostro habla. La manifestación del rostro es ya discurso. (Lévinas, 1999, 89)

Si existe un discurso, no es un discurso en el ámbito del logos, del lenguaje, sino anterior, y mucho más revelador, desde luego, que la palabra. En relación con este primigenio trato entre rostros, con los otrosrostros, el profesor Mèlich apunta:

Hay ética porque no sólo existo yo, sino que junto a mí y frente a mí hay alguien, un otro concreto, un rostro, y porque yo respondo del otro más allá del nexo biológico, de la norma social, o de la ley política. Hay ética, porque el poder no tiene la última palabra, porque las relaciones humanas, las relaciones con los otros, pueden sustraerse al poder. (Mèlich, 2004, 67)

Como este profesor señala, la relación ética con el otro no es una relación de poder, pues no se trata de un interés por dominar. Afirma Lévinas que el discurso con el otro es "experiencia de algo absolutamente extraño, 'conocimiento' o 'experiencia' pura, traumatismo del asombro." (Lévinas, 1999, 97) Como hemos dicho, es la experiencia de la desnudez del otro, de su rostro, que se nos muestra.

La desnudez del rostro no es lo que se ofrece a mí para que lo devele y que, por esto, me sería ofrecido, a mis poderes, a mis ojos, a mis percepciones en una luz exterior a él. El rostro se ha vuelto hacia mí y es esa su misma desnudez. Es por sí mismo y no con referencia a un sistema. (Lévinas, 1999, 98).

El autor que nos ocupa continúa afirmando que:

La relación con el rostro, no es conocimiento de objeto. La trascendencia del rostro es, a la vez, su ausencia de este mundo en el 
que entra, el destierro de un ser, su condición de exrranjero, de despojado o de proletario. El extrañamiento que es libertad, es también, extrañamiento, miseria. (...) El Otro, el libre, es también el extranjero. La desnudez de su rostro se prolonga en la desnudez del cuerpo que siente frío y vergüenza de su desnudez. (...) Hay allí entre el otro y yo una relación que está más allá de la retórica. (Lévinas, 1999, 98).

Más adelante este filósofo afirma: "La desnudez del rostro es indigencia. Reconocer a otro es reconocer un hambre. Reconocer a Otro es dar. Pero es dar al maestro, al señor, al que se aborda como "Usted" en una dimensión de grandeza." (Lévinas, 1999, 98-99) Perturbadora presencia la del otro que cuestiona "mi dichosa posesión del mundo." (Lévinas, 1999, 99)

El propio saber posee este carácter de estremecimiento perturbador. Es algo que también comienza con la crítica, con el rayo que taladra nuestro ignorante ensimismamiento, nuestro redondo solipsismo: "El saber cuya esencia es la crítica no puede reducirse al movimiento objetivo. Conduce hacia el Otro. Recibir al Otro, es cuestionar mi libertad." (Lévinas, 1999, 108)

Pero si bien la libertad me sitúa descaradamente frente al no-yo, en mí y fuera de mí, si consiste en negarlo o en poseerlo, sin embargo frente al Otro retrocede. La relación con el Otro no se convierte, como el reconocimiento, en gozo y posesión, en libertad. El Otro se impone como una exigencia que domina esta libertad, y a partir de aquí, como más original que todo lo que pasa en mí. El Otro, cuya presencia excepcional se inscribe en la imposibilidad ética de matarlo, en la que me encuentro, indica el fin de mis poderes. Si no puedo más poder sobre él, es porque desborda absolutamente toda idea que puedo tener de él. (Lévinas, 1999, 109)

En suma, para Lévinas la verdad presupone la justicia. En este sentido, "El pensamiento y la libertad nos vienen de la separación y de la consideración de Otro: esta tesis está en las antípodas del spinozismo." (Lévinas, 1999, 127)

En efecto, esta existencia e interpelación del otro resulta epistemológicamente necesaria. Sin él no podemos ni siquiera conocernos ni conocer el mundo. Tal es su importancia. Por eso, en el fondo, 
descubrimos que el otro siempre ha estado, incluso en el ejercicio de nuestra libertad, en la toma de nuestras decisiones, como punto de partida.

A continuación, nos vamos a ocupar de la realidad que nos revela esta mirada respetuosa, la mirada que sabe de la importancia del otro. Porque cuando se deshacen las verticalidades y la lógica del dominio que hemos descrito, entonces aparecería como lo auténtico el rostro ajeno. Entonces, como explica Rousseau, Emilio puede ser él, ya lejos de las convenciones de una sociedad opuesta a su naturaleza. Igual que el filósofo ginebrino, creemos, y así esperamos haberlo mostrado, que la humanidad puede alejarse de sí misma y extrañarse, cuando debido a oscuros mecanismos prefiere representar lo que no es, vivir una angustiada historia como las descritas por Kafka. La emancipación, en este sentido, pretende un retomo al estado natural en el que los hombres vuelven a ser rostros, bien distinto del estado actual, en que se hallan encorsetados en sus extraños prejuicios, cosificados por una lógica kafkiana e inhumana.

\subsection{La vida humana y la cultura como "no haber llegado nunca".}

Paulo Freire relata en un párrafo no muy conocido de uno de sus últimos libros que, siendo niño, descubrió el dinamismo del mundo y las relaciones humanas, se topó con el carácter imperfecto e inacabado de la realidad, en la que "todo fluye". De dicho descubrimiento resultó una suerte de desahogo y liberación.

Un día, a los cinco años, adiviné que había un desacuerdo en las relaciones entre mi padre y mi madre. No tenía, no podía tener conciencia de la profundidad y de la extensión de aquella situación. De repente me sentí como si la tierra desapareciese bajo mis pies. La falta de seguridad me hizo más frágil. Aquella noche dormí sobresaltado: soñé que me hundía en la orilla de un hondo barrizal de donde, con mucho esfuerzo, milagrosamente me salvaron. (...) La seguridad retornó en la medida en que, necesitado de ella, procuraba encontrarla no en ella misma sino en las relaciones entre mi padre y mi madre. Es alli donde debería estar. Por la mañana, cuando me levanté percibí satisfecho que mi seguridad estaba en la forma como mis padres hablaban entre sí y me hablaban. (Freire, 2002, 27)

Significativa anécdota que refiere el descubrimiento, trascendental, del carácter dinámico del mundo y las relaciones humanas por parte de un

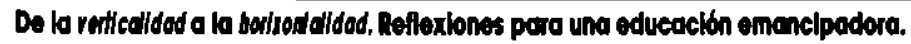


niño. Descubrimiento liberador, a todas luces. Liberador del miedo y la parálisis. De hecho, como hemos dicho, toda la pedagogía freiriana funda la liberación en el conocimiento profundo y cierto de que "el mundo no es, el mundo está siendo."

$\mathrm{Y}$, según hemos mostrado, abrirse a la movilidad es abrirse al otro. El otro es el rayo desafiante que, como afima Lévinas, imumpe en nuestra monotonía metafísica y la pone en movimiento. La totalidad, unívoca y ordenada, es cuestionada por un ser ajeno que introduce la inestabilidad en la inmovilidad del Mismo. En este sentido, escuchar a otra persona es estar dispuesto a ser cuestionado, a ser reducido a polvo, al mismo tiempo que de ello surge el individuo maduro.

Parecería que la sabiduría liberadora resulte del conocimiento de que, como expresa Bakunin, "la unidad real del universo no es más que la solidaridad y la infinidad absolutas de sus reales transformaciones, porque la transformación incesante de cada ser particular constituye la verdadera, la única realidad de cada uno, ya que todo el universo no es más que una historia sin límites, sin comienzo y sin fin." (Bakunin, 1977, 99) Curiosamente, es esta percepción del carácter efímero de la naturaleza humana y la historia la puerta para la liberación. Contrariamente a la parálisis propia del fanático, el hombre tolerante está abierto al cambio y la transformación. (Santos, 2001, 294-295) Dice Freire: “consciente de que puedo conocer social e históricamente, sé también que lo que sé no puede escapar a la continuidad histórica. El saber tiene historia. Nunca es, siempre está siendo." (Freire, 2002, 19)

Admitir que el conocimiento consiste en una re-creación continua implica la humildad de saber que uno no ostenta la verdad absoluta y puede estar equivocado. Por eso, la humildad es, según Freire, una auténtica llave del conocimiento:

Es necesario estar siempre a la espera de que un nuevo conocimiento surja, superando a otro que, ya habiendo sido nuevo, envejeció. (...) La historia es un llegar a ser como nosotros, seres limitados y condicionados, y como el conocimiento que producimos. Nada por nosotros engendrado, vivido, pensado o hecho explícito se da fuera del tiempo, de la Historia. Tener certeza, tener dudas, son formas históricas del estar siendo. (Freire, 2002, 20)

La horizontalidad aparecería en este contexto como la disposición a escuchar al otro, aceptando la transformación que nos provoca. Por eso, 
al desaparecer las concepciones inmovilistas de la cultura y aceptar su continuo progreso, sin miedo al extranjero que cuestiona nuestro mundo, se facilita que éste se exprese y aporte. La borizontalidad permite la participación común en una cultura que, hecha por todos, no se detiene en ninguna forma predeterminada. Se asume que la cultura está siendo, en permanente proceso de reconstrucción. En este sentido, por ejemplo, la identidad cultural ya no es algo fijo, sino que, como afirma García Martínez, se trata de un horizonte que nunca es alcanzado por completo y que también se halla en movimiento:

Sobre todo cuando se entiende, (...) que cualquier cultura no es sino el resultado de continuas negociaciones con el mundo exterior, mediante las cuales se afirma una identidad que sólo puede ser aprendida como algo que se crea continuamente. El nuevo estado de cosas lo que aporta, pues, no es otra cosa que un mayor espectro y un ritmo diferente en el desarrollo de tales negociaciones, es decir, modelos más complejos ( $\mathrm{y}$ más abiertos y transversales) de la construcción identitaria que se perfila más como horizonte que como hecho consumado. (García Martínez, 2003, 262-263)

Asumir el movimiento y el dinamismo del mundo, su continua transformación, por tanto, implica una renovación profunda y una liberación, en la medida en que ya es posible, entonces, expresarse y abrirse a la manifestación del otro, sin miedo, y a unas relaciones humanas borizontales. Dicha borizontalidad es sentida y aprendida por el sujeto educado, de manera que no necesita forzar a nadie a que no sea él mismo, ni teme manifestarse como individuo singular. Ya nadie coacciona a nadie y todos pueden expresarse, todos dan lo que de verdad son. Ya no hemos de abrimos paso a costa del otro, como sucede en los contextos de verticalidad y refleja la, tan idolatrada en nuestros tiempos, competitividad. Porque en la perspectiva horizontal toda victoria y toda derrota quedan superadas. No hay arribas ni abajos, ni buenos ni malos. Sólo la libertad de vivir sin premios y de recibir al otro sin mediaciones ni guiones que lo niegan. El gozo de recibir al otro que me cuestiona, pero en cuya interacción me proporciona la faz humana.

En síntesis, en la sociedad horizontal las relaciones humanas se autentifican, porque no necesitan repetir papeles ni justificar ménitos. Los hombres no precisan ya rendir cuentas a implacables jueces ni tratan de acoplarse a vanas expectativas sociales. Supone, nada menos, sustituir la 
visión del mundo como teatro, en la que hemos sido educados, como trama ya elaborada de antemano y repleta de personajes (que no personas). Desde el prisma de la horizontalidad la imagen del mundo y sus reglas cambian notablemente. Incluso, la disposición interior y auténtica para escuchar al otro y colaborar con él fomenta el progreso ${ }^{14}$.

Además, el grupo fraternal actúa como colchón de los malestares y continuamente revitaliza a sus miembros. Ya no es el amenazador conjunto de los otros hombres que se percibe desde la verticalidad. Al contrario, lo importante para el hombre libre de la coacción vertical es la creación colectiva, el proceso de construcción mutua y transformación. Y Freire, que sabe esto, contra toda apariencia, es muy realista. No nos habla de castillos en el aire cuando nos describe el dinamismo de la realidad y el carácter inacabado e histórico del hombre, proyectando desde ahí su pedagogía de la liberación. Se trata precisamente de un encuentro con la realidad, lejos de las figuraciones que nos han engañado demasiado tiempo, además de haber causado un enorme sufrimiento. $Y$ es justo por ese sufrimiento, que habríamos de tomar en serio, de una vez, el encuentro con nuestra responsabilidad para re-crear juntos la cultura, en un permanente proceso. En la borizontalidad liberadora el hombre ya no combate con la realidad ni trata de forzarla como si fuera algo ajeno y extraño, sino que la asume y forma parte de ella, realizándose como ser humano y dando rienda suelta a su amor olvidado.

BiBLIOGRAFÍA

Adorno, TH. W. (1998) Educación para la emancipación. Madrid, Morata. Ayuste, A. et al. (1999) Planteamientos de la pedagogía crítica. Comunicar y transformar. Barcelona, Graó.

Bakunin, M. (1977) Federalismo, socialismo y antiteologismo. Madrid, Aguilera.

Barrio, J. M. (2003) "Tolerancia y cultura del diálogo", Revista española de pedagogia, 224, 131-152.

Bernal, A. (2003) "La construcción de la identidad personal como proyecto de educación moral. Supuestos teóricos y delimitación de competencias", Teoría de la Educación. Revista interuniversitaria, 15, 129-160. 
Bourdieu, P. (2000) La distinción. Criterio y bases sociales del gusto. Madrid, Taurus.

Bourdieu, P y Passeron, J. CL (2001) La reproducción. Elementos para una teoria del sistema de enseñanza. Madrid, Popular.

Camus, A. (1995) La peste. Barcelona, RBA.

Camus, A. (2001) El hombre rebelde. Madrid, Alianza.

Díaz, C. (1978) El anarquismo como fenómeno politico moral. Madrid, Zero.

Estrada, J. A. (1990) La teoría crítica de Max Horkbeimer. Del socialismo ético a la resignación. Granada, Universidad de Granada.

Ferrater Mora, J. (1998) Diccionario de filosofía. Barcelona, Ariel.

Ferrière, A. (1982) La escuela activa. Barcelona, Herder.

Freire, P. (2001) Pedagogía de la indignación. Madrid, Morata.

Freire, P. (2002) A la sombra de este árbol. Barcelona, El Roure.

Fromm, E. (1974) El arte de amar. Buenos Aires, Paidós.

Fromm, E. (1976) El miedo a la libertad. Buenos Aires, Paidós.

Fromm, E. (1992) Psicoanalisis de la sociedad contemporánea. Hacia una sociedad sana. Madrid, Fondo de Cultura Económica.

Fromm, E. (1999) ¿Tener o ser? Madrid, Fondo de Cultura Económica.

Foucault, M. (2001) Un diálogo sobre el poder y otras conversaciones. Madrid, Alianza.

García Carrasco, J. y García del Dujo, A. (2001) La teoría de la educación en la encrucijada, Teoria de la educación. Revista interuniversitaria, $13,15-43$.

García Martínez, A. (2003) Identidad y cultura: efectos en la educación intercultural, Pedagogia Social. Revista interuniversitaria, 10, Segunda época, 253-264.

García Moriyón, F. (1990) Del socialismo utópico al anarquismo. Madrid, Cincel.

Gramsci, A. (1972) Introducción a la filosofía de la praxis. Barcelona, Península.

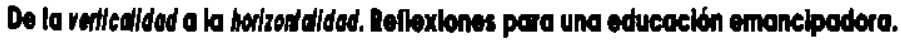


Goodman, P. (1976) La des-educación obligatoria. Barcelona, Fontanella. Holt, J. (1982) El fracaso de la escuela. Madrid, Alianza.

Horkheimer, M. (1998) Teoría crítica. Buenos Aires, Amorrortu.

Horkheimer, M. (2002) Crítica de la razón instrumental. Madrid, Trotta.

Illich, I. (1974) La sociedad desescolarizada. Barcelona, Barral.

Illich, I. (1978) La convivencialidad. Barcelona, Barral.

Jaspers, K. (1958) Filosofía (2 vols.). Madrid, Revista de Occidente-Ediciones de la Universidad de Puerto Rico.

Jaspers, K. (2001) Psicopatología general. México, Fondo de Cultura Económica.

Kafka, F. (1998) El proceso. Madrid, Alianza.

Lévi-Strauss, C. (1996) Raza y cultura. Madrid, Cátedra.

Lévinas, E. (1999) Totalidad e infinito. Ensayo sobre la exterioridad. Salamanca, Sígueme.

López Quintás, A. (1995) “La tolerancia y la defensa entusiasta de la verdad", Revista española de pedagogía, 251, 321-334.

Lukács, G. (1984) Historia y consciencia de clase (2 volúmenes). Madrid, Sarpe.

Marcuse, H. (1998) El hombre unidimensional. Ensayo sobre la ideología de la sociedad industrial avanzada. Barcelona, Ariel.

Marx, K. (1993) Manuscritos. Barcelona, Altaya.

Mélich, J. C. (2004) La lección de Auscbreitz. Barcelona, Herder.

Neill, A. S. (1994) Summerbill. Un punto de vista radical sobre la educación de los niños. Madrid, Fondo de Cultura Económica.

Peña, J. V. y Rodríguez, M. C. (2002) Identidades esquemáticas de género en la escuela: a propósito del primer aniversario de la muerte de Pierre Bourdieu, Teoría de la Educación. Revista interuniversitaria, 14, 235-263.

Pérez Gómez, A.I. (1997) “La perspectiva crítica en educación. socialización y educación en la época postmoderna". (Ponencia presentada al Congreso Educación, Crítica e Innovación. Vitoria, febrero, 1997). 
Popper, K. (1983) Conjeturas y refutaciones. Barcelona, Paidós.

Popper, K. (1997) El mito del marco común. Barcelona, Paidós.

Reich, W. (1972) Psicología de masas del fascismo. Madrid, Ayuso.

Reich, W. (1985) La revolución sexual. Para una estructura de carácter autónoma del bombre. Barcelona, Planeta-Agostini.

Reimer, E. (1981) La escuela ba muerto. Alternativas en materia de educación. Barcelona, Guadarrama.

Rousseau, J. J. (1998) Emilio, o De la educación. Madrid, Alianza.

Santos, M. (2001) "El saber de la escuela", Revista de Ciencias de la Educación, 187, 287-298.

Santos, M. (2002) "La tolleranza come valore educativo: ragioni e conseguenze", Orientamenti Pedagogici. Rivista Internazionale de Scienze dell' educazione, 49 (3), 421-434.

Santos, M. (2003a) La tolerancia como valor: clarificación conceptual e implicaciones educativas. Granada, Editorial Universidad de Granada.

Santos, M. (2003b) La tolerancia en la escuela: el modelo pedagógico socrático, Revista de Ciencias de la educación, 194, 157-173.

Santos, M. (2003c) Hacia una noción educativa de tolerancia, Enseñanza. Anuario interuniversitario de didáctica, vol. 21, Pp. 363-378.

Santos, M. (2004) Participación, democracia y educación: cultura escolar y cultura popular. Revista de educación. (MEC) En prensa.

Santos, M. (2005) “Antecedentes del valor educativo 'tolerancia", Revista española de pedagogía. En prensa.

Schopenhauer, A. (1998) El mundo como voluntad y representación. México, Porrúa.

Spring, J. (1987) Introducción a la educación radical. Barcelona: Akal.

Taberner, J. y Rojas, C. (1988) Marcuse, Fromm, Reich: El freudomarxismo. Madrid, Cincel. 


\section{NOTAS}

I Aunque bien podría decirse que se impone un cierto malestar en la vida humana que resulta intrínseco a ella. Se trata de lo señalado por un pesimismo metafísico que enfatiza que la existencia humana, desprovista de un claro sentido, tal y como la abordan los existencialismos de cuño ateo, es la de un estar arrojados, la de ser sueños de un sueño no soñado por nadie. Hay toda una tradición ancestral que enarbola este bien razonable pesimismo, visto lo visto. Señero es en esta perspectiva Schopenhauer, respetable y máximo exponente de ella, cúspide de un fatalismo desamparado que, al menos, acierta a referirse a una hermandad de todos los hombres en el sufrimiento, una suerte de ética de la compasión (Schopenhauer, 1998, 289). A esto, a su modo, se suma también el más reciente pensador Albert Camus, del que admiramos profundamente el descomunal esfuerzo que realiza por encontrar una razón para la esperanza, para el amor entre los seres, el altruismo y la lucha por un mundo mejor. Porque, según este autor francés, para el hombre educado en el sufrimiento, desmontadas las desmesuradas esperanzas de los viejos sueños metafísicos, puede llegar el tiempo de, a pesar de todo, no cejar en el empeño de comunicarse y pasear por los hilos que median entre los humildes seres humanos, amándolos en su sencillez. (Camus, 1995, 2001) De todo esto nos ocupamos en otro artículo, actualmente inédito.

2 En palabras del profesor Estrada, en la idea de 'carácter social', "Erich Fromm considera la estructura libidinosa freudiana como una combinación de instintos humanos y factores sociales y busca determinar su función social. Este es el punto de partida de los estudios de los miembros de la Escuela de Frankfurt sobre la 'personalidad autoritaria' y sus vinculaciones con el fascismo." (Estrada, 1990, 28) "Horkheimer desconfía, con el psicoanálisis y con la crítica maniana a las ideologías, de lo que los individuos creen. Hay que atender a la praxis porque la conciencia humana se adapta a las acciones de los individuos. Su pensamiento asimila la desconfianza de Marx y Freud ante las apariencias, ante lo que los individuos creen o afirman que creen. Por eso la TC [Teoría Crítica] es ante todo crítica cultural, antiideológica." (Estrada, 1990, 27-28)

- Ellos valoran, frente a la función ideológica de las creencias, una función crítica del pensamiento que contribuye positivamente al desvelamiento de las ideologías y que, por tanto, incide en una transformación de la sociedad. Por ejemplo, Lukacs destaca que la lucha por la emancipación será no sólo en el plano de la realidad económica y social, sino también en el plano de las ideas:

${ }^{a}$ El proletariado se realiza a si mismo al suprimirse y superarse, al combatir hasta el final su lucha de clase y producir asi la sociedad sin clases. La lucha por esta sociedad, mera fase de la cual es incluso la dictadura del prolecariado, no es sólo una lucha con el enemigo externo, con la burguesía, sino también y al mismo tiempo una lucha del proletariado consigo mismo, con los efectos destruetores y humillantes del sistema capitalista en su consciencia de clase. (...) El proletariado no puede ahorrarse ninguna autocrítica, pues sólo la verdad puede aportarle la victoria: la autocrítica ha de ser, por lo tanto, su elemento vital." (Lukacs, 1984, 166) 
Además, Gramsci, en su valoración, precisamente, de la función crítica y transformadora del pensamiento, afirmará: “La filosofía es la crítica y la superación de la religión y del sentido común; entendida de este modo, coincide con el "buen sentido', que se contrapone al sentido común." (Gramsci, 1972, 15) y "una filosolía de la praxis no puede dejar de presentarse inicialmente como una actitud polemica y crítica, como superación del modo de pensar precedente y del pensamiento concreto existente (o del mundo cultural existente). Es decir, debe presentarse ante codo como crítica del 'sentido común' (...) (Gramsci, 1972, 21). Es precisamente a través de la toma de conciencia de la función legitimadora de las creencias y concepciones del mundo que nos conforman, como apunta también Marcuse que habría de comenzarse el proceso de liberación: "Toda liberación depende de la toma de conciencia de la servidumbre, y el surgimiento de esta conciencia se ve estorbado siempre por el predominio de necesidades y satisfacciones que, en grado sumo, se han convertido en propias del individuo." (Marcuse, 1998, 37) Y, por supuesto, la Teoria Crítica del primer Horkheimer se plantea en una dirección muy semejante:

"Horkheimer desconffa, con el psicoanálisis y con la crítica marxiana a las ideologías, de lo que los individuos creen. Hay que atender a la praxis porque la conciencia humana se adapta a las acciones de los individuos. Su pensamiento asimila la desconfianza de Marx y Freud ante las apariencias, ante lo que los individuos creen o afirman que creen. Por eso la TC [Teoría Crítica] es ante todo crítica cultural, antiideológica." (Estrada, 1990, 27-28)

- Foucault pretende incluso llegar más lejos que Freud y Marx en la denuncia y comprensión de esta omnipresencia del poder en las relaciones humanas y la psique. Así, afirma: "Manx y Freud quizá no bastan para ayudarnos a conocer eso tan enigmático, a la vez visible e invisible, presente y oculto, ocupado en todas partes, que se llama el poder. La teoría del Estado, el análisis tradicional de los aparatos de Estado, no agotan sin duda el campo de ejercicio y funcionamiento del poder." (Foucault, 2001, 31)

5 En la base de los fenómenos fascistas y autoritarios estaría esta suerte de vivencia enajenada, que, según Fromm, es buscada por el propio sujeto (a menudo inconscientemente) que siente lo que él denomina "miedo a la libertad" (Fromm, 1976). Debido a dicho miedo hacia lo que la libertad y la autonomía implican de separatividad, a la amarga sensación de soledad e incertidumbre que acompañan a los primeros pasos del sujeto hacia la autonomía y madurez psiquicas, el individuo se anula y enajena, en una suerte de postura regresiva a estadios de inmadurez.

- En cierto trabajo anterior, expusimos algunas razones que evidencian cómo la búsqueda de la verdad es una tarea colectiva que requiere, por tanto, la tolerancia y el respeto. Aludimos, en especial, a la filosofía socrática, al falsacionismo popperiano y al perspectivismo de Orrega y Gasset. (Santos, 2003)

, Citemos el impresionante final de la novela $E$ l proceso, la escena en la que se consuma una condena sin sentido, el lugar adonde conduce una lógica implacable que opera por encima del personaje y lo convierte en un impotente pingajo. No tiene desperdicio (las cursivas son nuestras): 
“Después, uno de los señores se desabrochó la levita y, de una vaina que llevaba colgada a un cinto que le rodeaba el chaleco, sacó un largo cuchillo de carnicero, estrecho y afilado por ambos lados. Lo sostuvo en alto y comprobó el filo a la luz. De nuevo se iniciaron las repugnantes cortesias; por encima de K., el uno le pasaba el cuchillo al otro; éste lo devolvía, también por encima de $\mathrm{K}$. Ahora $K$. sabia exactamente que su deber babría sido coger él mismo el cuchillo que pasaba de mano en mano por encima de el, e introducirlo en su cuerpo. Pero no lo hizo; lo que hizo lue mover el cuello, todavía libre, y mirar a su alrededor. No podía satisfacer del todo aquella exigencia ni librar a las autoridades de su trabajo, pero la responsabilidad de aquel último error no era suya sino de quien le había quitado el resto de las fuerzas que hubiera necesitado. Sus ojos se clavaron en el último piso de la casa lindante con la cantera. Del mismo modo que se enciende una llama, se abrieron de golpe los cristales de una ventana; una persona, una figura débil y vacilante por la distancia y la altura, se inclinó mucho hacia adelante con un brusco movimiento y tendió los brazos aún más hacia adelante. ¿Quién era? ¿Un amigo? ¿Una buena persona? ¿Alguien que sentía compasión? ¿Alguien que quería ayudar? ¿No habría más de uno? ¿Eran todos? ¿Era una última ayuda? ¿Quedaban objeciones que habían olvidado? Seguro que quedaba alguna. La logica es ciertamente inconmovible, pero a une persona que quiere vivir no le opone resistencia. iDónde estaba el juez que no habia visto nunca? ¿Dónde estaba el alto tribunal al que nunca había llegado? Levantó las manos y separó todos los dedos. (...) Pero las manos de uno de los señores se posaban ya en la garganta de K., mientras el otro le hundía profundamente el cuchillo en el corazón y lo hacía girar dos veces. Con los ojos vidriosos, $\mathrm{K}$ vio aún cómo los señores, muy cerca de su cara, mejilla contra mejilla, observaban la decisión. 'iComo un perro!', dijo; era como si la vergüenza bubiese de sobrevivirle." (Kafka, 1998, 233-234)

- Esta convicción acerca del poder, como elemento que corrompe profundamente el corazón humano, es puesta de relieve con insistencia por los pensadores anarquistas. Gran parte de su filosolía conduce también a esta evidencia. Así, en Bakunin, por ejemplo, podemos leer: 'Nada es tan peligroso para la moral privada del hombre como el hábito del mando. El hombre mejor, el más inteligente, el más desinteresado, el más generoso, el más puro, se echa a perder infaliblemente y siempre en ese oficio. Dos sentimientos inherentes al poder producen siempre esa desmoralización: el desprecio de las masas populares y la exageración del propio mérito." (Bakunin, 1977,140 ) En la filosofía libertaria y el llamado socialismo ut6́pico decimonónico resulta central la crítica a esta verticalidad inserta en el hombre, y que se manifiesta en los fenómenos de dominio y poder. Se trata de un punto básico de dichas filosofias. Se pone de manifiesto el efecto deshumanizador del poder, como algo opuesto a la naturaleza humana y la felicidad del individuo, que se basan, por contra, en el apoyo mutuo. Son conocidos los esfuerzos de Kropotkin por justificar el papel evolutivo que en el mundo natural han tenido los comportamientos altruistas y este apoyo mutuo, en oposición a la idea de una contienda universal entre los individuos en la que la supervivencia del más fuerte es la regla y el motor de la evolución. (Díaz, 1978, 34-41; Garcla Moriyón, 1990, 59)

- Hesíodo sitúa la guerra de los hombres entre sí en las estirpes degeneradas que se alejan de la mítica "Edad de Oro" que nos refiere en Los trabajos y los dias. (Trab. 
106-195) La imaginación de una edad dorada cuya principal característica es la convivencia pacífica y la colerancia entre los seres humanos ha tenido cierta recurrencia en la historia.

10 El desartollo de esta idea en Fromm se ofrece de forma sintética y clara en su conocida obrita El arte de amar, que resume sus primeras consideraciones al respecto. (Fromm, 1974) Nos viene a explicar que el amor maduro requiere un estado determinado en el desarrollo psíquico humano, una salud mental que en absoluto abunda entre nosotros, porque como afirma en esta obra $y$ en otras posteriores, nuestras sociedades están enfermas. (Fromm, 1992)

I1 La "tolerancia" se ha entendido, básicamente, de tres maneras, al menos desde el comienzo de su utilización en los siglos de la Reforma religiosa en Europa. (Santos, 2002) Se consideran, pues, estos tres sentidos: a) una tolerancia como permisividad absoluta, como un "todo vale" sin límite; b) una tolerancia como apreciación positiva de la diferencia, que acepta que el otro es poseedor de una perspectiva que nos puede enriquecer; $c$ ) una tolerancia negativa que equivale a un mero consentimiento de la diferencia por parte de quien cree poseer la verdad. De ellos, el que conecta con lo que estamos describiendo es el segundo, que implica una aceptación e inclusión positiva del orro en nuestro mundo. Esta forma de entender la tolerancia es explicada, descrita y justificada en Santos, 2002; 2003a; 2003b; 2005; Barrio, 2003; López Quintás, 1995. Por citar algunos estudios en nuestro ámbito, porque la bibliografía nacional e intemacional es abundantísima En cualquier caso, esta tolerancia se relaciona claramente con lo que aqul venimos denominando borizontalidad.

12 La psicología de corte psicoanalítico enseña, en efecto, que lo que verdaderamente opera en el hombre es su intimidad inconsciente y pulsional. Aht se hallan los verdaderos motivos de nuestras acciones, de modo que lo desarrollado en el discurso verbal consciente puede no ser más que una racionalización que a veces incluso encubre nuestros motivos auténticos para obrar. Por eso, la palabra puede engañar y ocultar, resultando vacía, muerta e incluso opuesta al sentido en que marchamos realmente. Es decir, se puede elaborar toda una argumentación racional sobre la necesidad de ser tolerantes, pero en los niveles profundos e inconscientes de nuestra psique, podemos no creer lo que nosotros mismos decimos. Por eso, a pesar de defender verbalmente la tolerancia, podemos ser de hecho profundamente intolerantes. Sobre esto, afirma Ferrater Mora:

"Freud estima que no hay actos de ninguna clase, incluyendo actos verbales y sueños, que no tengan una causa Generalmente se supone que los actos que el hombre ejecuta, las ideas que tiene, las palabras que dice, etc., son explicables en virtud de motivos relativamente bien determinados o, en todo caso, determinables. Se sabe que muchas veces no se dice lo que se había querido decir, o se hace algo que no se había querido hacer, o se tienen sueños 'inexplicables' o 'extraños'. Se sabe asimismo que en ocasiones se producen inhibiciones, se experimentan angustias, se tienen sentimientos de culpabilidad, etc. Freud trató de dar cuenta y razón de todas estas manifestaciones humanas a base de un mecanismo constituido por fuerzas y actividades de tal índole que mucho de lo que estaba psíquicamente presente debía remitir a algo que estaba ausente y que era, además, en principio, inescrutable." (Ferrater Mora, 1998, 2950). 
Todos estos fenómenos apuntan a una realidad subyacente que puede entrar en conflicto con la consciencia y lo que aparentamos.

1) El otro ya se halla en nosotros incluso antes del aprendizaje y la cultura, en tanto somos especie. En este sentido, los profesores García Carrasco y García del Dujo señalan como colofón de un artículo en el que precisamente proponen deconstruir los estratos que la evolución cultural ha ido creando hasta llegar al sustrato más básico del proceso educativo en la especie humana:

La tarea fundamental de la reflexión sobre la educación es precisamente estar atento a todo ese recorrido de los humanos como especie dentro del mundo de la vida, recorrido que empieza precisamente reproduciendo el diseño de la especie en un cuerpo que no puede sobrevivir sino incorporándose a un espacio relacional compuesto por comunidades de humanos; ahí toma modos de ser y estilos de hacer, desarrolla unas capacidades y se inhibe en ocras; allí es donde construye la obra más maravillosa, compleja, exclusiva, participada, comprometida, afiliada, poliédrica, a la que todos señalamos como identidad. (Garcfa Carrasco y García del Dujo, 2001, 41) En el origen siempre nos encontramos con el otro.

14 Según Popper, el avance científico y el progreso en el conocimiento del mundo requiere la confrontación de ideas. Su teorla falsacionista de la ciencia afirma que una ley científica siempre es provisional y ha de ser probada de continuo (debe, por su forma, prestarse a ello, es decir, ser falsable), para que si se encuentra un hecho que la refute, sea eliminada. Se trata de elaborar muchas hipótesis para explicar un mismo fenómeno, cuantas más mejor, y que compitan entre ellas en pos del mejor ajuste a la realidad. En todo caso, nuestro conocimiento nunca se compone de certezas absolutas, sino de verdades provisionales. (Popper, 1983) 